\title{
Progression and Revenue Effects of Income Tax Reform
}

\author{
KOEN CAMINADA \\ Leiden University, Faculty of Law, Department of Public Finance, P.O. Box 9521, 2300 RA Leiden, The Netherlands \\ KEES GOUDSWAARD \\ Leiden University, Faculty of Law, Department of Public Finance, P.O. Box 9521, 2300 RA Leiden, The Netherlands
}

\begin{abstract}
Usually, only initial revenue effects of personal income tax reforms are considered. However, a tax reform characterized by base broadening in exchange for rate reduction can reduce the income elasticity of tax reverue. In that case, the increase in revenue after income growth will be relatively smaller: the tax reform has a negative effect on revenue in the second period. Using the microtax model of the Central Planning Bureau we simulated the effects of the Dutch "Oort" reform 1990 on revenue elasticities and, consequently, on tax revenue. The income tax revenue elasticity declined by 17 percent which caused an additional revenue loss of 0.6 percent in 1990, rising to 3.8 percent in 1993 .
\end{abstract}

Key words: tax reform, progression, income tax revenue elasticity, budgetary effects

\section{Introduction}

In the 1980 s, many OECD countries implemented tax reforms characterized by base broadening, reduction of tax rates, and flattening of the rate structure (Cnossen and Messere, 1990). Generally, these reforms are designed under a revenue constraint. In some cases, for example, a framework of revenue neutrality has been chosen. However, in this context, only initial effects of tax reform on revenue-that is, effects at unchanged pretax incomes-are taken into account. Not only behavioral responses but also general income growth are ignored. In this paper we show that there will be additional effects on revenue in the years beyond the reform. The reason is that base broadening in exchange for rate reduction can reduce the elasticity of income tax revenue. This implies that the increase in revenue in case of nominal income growth will be smaller. Such additional effects are often overlooked in practice but can nonetheless be substantial.

The revenue elasticity of the personal income tax with respect to income has been analyzed by Tanzi (1969, 1976), Wellink (1975), Hutton and Lambert (1980, 1982), Fries, Hutton, and Lambert (1982), and Ram (1991). These authors have estimated elasticities with historical, macro, or cross-section data. In this paper we estimate revenue elasticities with a micro model. This approach makes it possible to identify determinants of the change in revenue elasticity (in line with the work of Fries, Hutton, and Lambert, 1982). We simulate the effects of a major tax reform in the Netherlands (the "Oort" reform) on the income 
tax revenue elasticity. Consequently, we are able to calculate the impact of this reform on tax revenue after nominal pretax income growth.

The paper is organized as follows. In Section 2 we define and elaborate the income elasticity for a progressive tax system. Section 3 deals with the effects of base broadening. Sections 4 and 5 document the Dutch tax reform in 1990 and the model used to analyze the effects of this reform. Sections 6 and 7 present empirical results for the income elasticities and the revenue effects. Section 8 concludes the paper.

\section{Income elasticity in a progressive tax system}

Our analysis of the income elasticity of a tax system starts at the micro level. The revenue elasticity of an individual taxpayer $i$ with respect to nominal pretax income is

$$
\pi_{i}=\frac{Y_{i}}{T_{i}} \cdot \frac{d T_{i}}{d Y_{i}}
$$

This micro elasticity concept, also referred to as liability progression, is commonly used in the literature on tax progression and redistribution (Musgrave and Thin, 1948; Jakobsson, 1976; Kakwani, 1977; Norregaard, 1990). ${ }^{1}$ In this paper we focus on the responsiveness of tax revenue to nominal income growth. Therefore we define the macro income elasticity $\left(\pi_{a v}\right)$ as the weighted average of the individual income elasticities:

$$
\pi_{a v}=\frac{\sum_{i=1}^{n} \pi_{i} \cdot T_{i}}{\sum_{i=1}^{n} T_{i}}
$$

$\pi_{a v}$ is the proportionate change in $\Sigma T_{i}$ from a small equiproportionate increase in all pretax incomes. It can be used as a measure for the macro revenue elasticity of a tax system (Hutton and Lambert, 1980, p. 905; OECD, 1984, pp. 38-41).

We start by deriving the income elasticity in a piecewise linear tax system with $k$ tax rates $t_{1}<t_{2}, \ldots,<t_{k}$. Taxable income is defined as pretax income $Y_{i}$, minus $m$ deductions $D_{i, m}$. With $B_{j}$ denoting the income ceiling of the $j$ th tax bracket, tax liability for individuals in the $k$ th bracket can be written as

$$
\begin{aligned}
& T_{i}=\sum_{j=1}^{k-1} t_{j} \cdot B_{j}+t_{k} \cdot\left[Y_{i}-\sum_{m=1}^{z} D_{i, m}-\sum_{j=1}^{k-1} B_{j}\right]=t_{k} \cdot\left[Y_{i}-\sum_{m=1}^{2} D_{i, m}-\sum_{j=1}^{k-1} B_{j} \cdot\left[\frac{t_{k}-t_{j}}{t_{k}}\right]\right] \\
& \quad \text { for } Y_{i} \geq \sum_{j=1}^{k-1} B_{j}+\sum_{m=1}^{z} D_{i, m} .
\end{aligned}
$$


We denote the income elasticity of deductions by $\alpha_{i, m}$. In most cases deductions are either a fixed amount, such as personal exemptions $\left(\alpha_{i, m}=0\right)$, or a fixed proportion of pretax income $\left(\alpha_{i, m}=1\right)^{2}$. From (3), the income tax elasticity for individuals in the $k$ th income bracket is then given by (see Fries, Hutton, and Lambert, 1982, p. 149):

$\pi_{i}=\frac{t_{k}\left[Y_{i}-\sum_{m=1}^{z} \alpha_{i, m} \cdot D_{i, m}\right]}{T_{i}}=1+\frac{\sum_{j=1}^{k-1} B_{j} \cdot\left(t_{k}-t_{j}\right)}{T_{i}}+\frac{t_{k} \cdot \sum_{m=1}^{z}\left(1-\alpha_{i, m}\right) \cdot D_{i, m}}{T_{i}}$.

Equation (4) shows that the income elasticity depends on the rate structure and on the size and income elasticities of deductions.

\section{Tax reform by broadening the tax base}

In this section we illustrate the effect on the income elasticity $\pi_{i}$ of eliminating the deduction $D_{i, 1}$, in exchange for a uniform proportionate reduction in tax rates sufficient to keep revenue constant at the initial level and distribution of pretax income. Such a proportionate reduction in tax rates clearly has no effect on the income elasticity $\pi_{i}$.

The income elasticity after tax reform $\left(\pi_{i}^{\prime}\right)$ is given by

$$
\pi_{i}^{\prime}=\frac{Y_{i}-\sum_{m=2}^{z} \alpha_{i, m} \cdot D_{i, m}}{Y_{i}-\sum_{m=2}^{z} D_{i, m}-\sum_{j=1}^{k-1} B_{j} \cdot\left(\frac{t_{k}-t_{j}}{t_{k}}\right)}
$$

It can be shown from equations (4) and (5) that, if there is no change in the individual's income bracket and $\alpha_{i, 1} \leq 1$ (a condition that is normally satisfied), then $\pi_{i}^{\prime}<\pi_{i}$. Thus, under these circumstances, the elimination of a deduction reduces the income elasticity of the tax system. This effect is greater, the less income-elastic the deduction is. The intuitive reasoning is quite simple. If deductions are income-related, pretax income growth causes a smaller increase in taxable income compared to the case that deductions are income inelastic. Income-inelastic deductions, such as personal exemptions, imply a higher liability progression and thus, if eliminated, a larger reduction in liability progression.

However, the elimination of $D_{i, 1}$ can affect the tax bracket that individual $i$ is in. For those individuals falling in higher brackets because of base broadening, there will be an additional effect on $\pi_{i}$. It can be shown that this threshold effect is always positive. Thus, in case of a tax jump, the total effect of base broadening on $\pi_{i}$ becomes theoretically ambiguous. The magnitude of the threshold effects depends on the degree of progression of the rate structure.

A tax reform as discussed above is revenue neutral with unchanged income. However, in case the base-broadening effect is larger than the threshold effect, the micro elasticities 
and thus the macro revenue elasticity $\left(\pi_{a v}\right)$ as defined in Section 2 will fall. This implies that the increase in revenue after income growth is smaller than it would be without the tax reform. ${ }^{3}$ In addition, there is revenue loss. ${ }^{4}$

\section{Dutch tax reform in 1990}

On January 1, 1990, a revision of the personal income tax based on the proposals of the Oort Commission became effective in the Netherlands. The main changes in the new legislation were as follows (De Kam, 1993):

- The personal wage and income tax was fully integrated with the general social security contributions, with a combined rate and uniform base.

- The tax base was broadened by Dfl 97 billion or by 63 percent, mainly by eliminating the deductibility of general social security contributions (Dfl 50 billion) and by lowering personal exemptions (Dfl 39 billion). ${ }^{5}$ The standard personal exemption was reduced by 38 percent in 1990.

- The number of tax brackets was reduced from nine to three. The first income bracket was to be taxed at 35.1 percent (a combination of 13 percent taxes and 22.1 percent premiums). In the second and third income brackets, rates were set at 50 percent and 60 percent, respectively. The new top rate of 60 percent is much lower than the top rate of 7 percent in the old system. The rate structure has thus been made less progressive.

Although the proposals of the Oort Commission were revenue neutral, the actual reform package implied a tax reduction amounting to 0.8 percent of GDP.

On the basis of the analysis in Sections 2 and 3, it can be expected that this tax reform has caused a decrease in the macro revenue elasticity. Three elements are relevant here. First, we expect a moderate negative effect from the elimination of the deductibility of social security contributions. This deduction is income related but with an average income elasticity $\left(\alpha_{a v}\right)$ less than 1 because there is an income ceiling. The second factor, the lowering of the fixed personal exemptions, will have a more substantial negative effect. Although the personal exemptions can be annually adjusted for inflation, we initially do not incorporate this inflation correction in the income tax in our calculations. Following the Ministry of Finance, we consider the correction of the income ceilings of tax brackets and of personal exemptions for inflation a discretionary policy measure. ${ }^{6}$ Finally, the revenue elasticity is also expected to decline because of the change in the rate structure.

Obviously, other factors, in particular changes in the pretax income distribution (from behavioral effects) and changes in the number of taxpayers also have an impact on the revenue elasticity (Ram, 1991; Fries, Hutton, and Lambert, 1982; Wellink, 1974). Our analysis, however, focuses on the (partial) effect of the tax reform.

\section{The microtax model}

For the calculation of the revenue elasticity of the income tax we used the microtax model of the Central Planning Bureau (1988, 1990). This static spreadsheet micro model generates 
the trajectory from gross to net earnings (and thus tax burdens) for different socioeconomic income groups (employees, selfemployed, social security beneficiaries, civil servants, social welfare recipients). A selection of nearly 200 representative hypothetical income recipients is made, differentiated by income source, income level, and personal exemptions for single persons or sole earners. The data of the model are taken from the annual Dutch Macro Economic Outlook.

Microtax is well suited to simulate the effects of the Oort reform on the income tax revenue elasticity. The model is annually available for the years 1988 (before Oort) until 1993 (after Oort). It can be used to simulate a marginal equiproportionate nominal growth of all pretax incomes and then to calculate individual income tax elasticities and the macro revenue elasticity $\pi_{a v}$ (see Section 2). Lambert and Pfähler (1992, p. 13) also conclude that the most promising approach in this kind of empirical work seems to be through (micro) simulation.

The model only includes standard deductions (such as standard deduction for cost of working and deduction for sickness and unemployment insurance paid by employees). Other individual specific deductions are not taken into account (such as interest, charitable gifts, exceptional medical costs, alimony payments). The fact that the model does not include specific individual deductions is not a serious problem for our analysis. Neglecting these deductions (in 198920 percent of total deductions) certainly affects the level of the revenue elasticity because some of them are very income elastic. On the other hand, it seems unlikely to significantly affect the change in revenue elasticity resulting from the tax reform in our empirical study. This is because the Oort reform mainly refers to standard deductions. Of the total amount of base broadening, 96 percent is accounted for in microtax. Thus, the limitations of the model do not seriously affect our results.

\section{Empirical results}

With microtax we calculated all individual tax elasticities (for the total of income tax and general social security contributions) for the various socioeconomic groups, for the years 1989 and 1990. Figure 1 illustrates the results for employees at different income levels. It appears that after the tax reform elasticities have fallen almost across the board. The figure also illustrates the reduction of the number of tax brackets. As can be seen from equation (4), every income ceiling causes a jump in individual tax elasticity $\left(\boldsymbol{\pi}_{i}\right)$. Next, we derived weighted average elasticities for each subgroup and finally a weighted average revenue elasticity for the total population $\left(\pi_{a v}\right)^{8}$ Using this procedure, we calculated a total revenue elasticity of 1.475 in 1989 and of 1.220 in 1990 . The overall decline in revenue elasticity by 17 percent can be characterized as a structural change: calculations for earlier and later years indicate almost stable revenue elasticities.'

In order to disentangle the effects of the various elements of the tax reform we have used equation (4). First, we calculated the partial effect of eliminating the deductibility of social security contributions. This accounts for 15.3 percent of the decline in the revenue elasticity. As expected, this effect is only small because this specific deduction is rather strongly related to income $\left(\alpha_{a v}=0.809\right)$. The reduction of personal exemptions accounts, also in line with our expectations, for a much larger share (54.9 percent) of the decline in the revenue elasticity. Furthermore, 15.1 percent of the decline in the revenue elasticity can be 


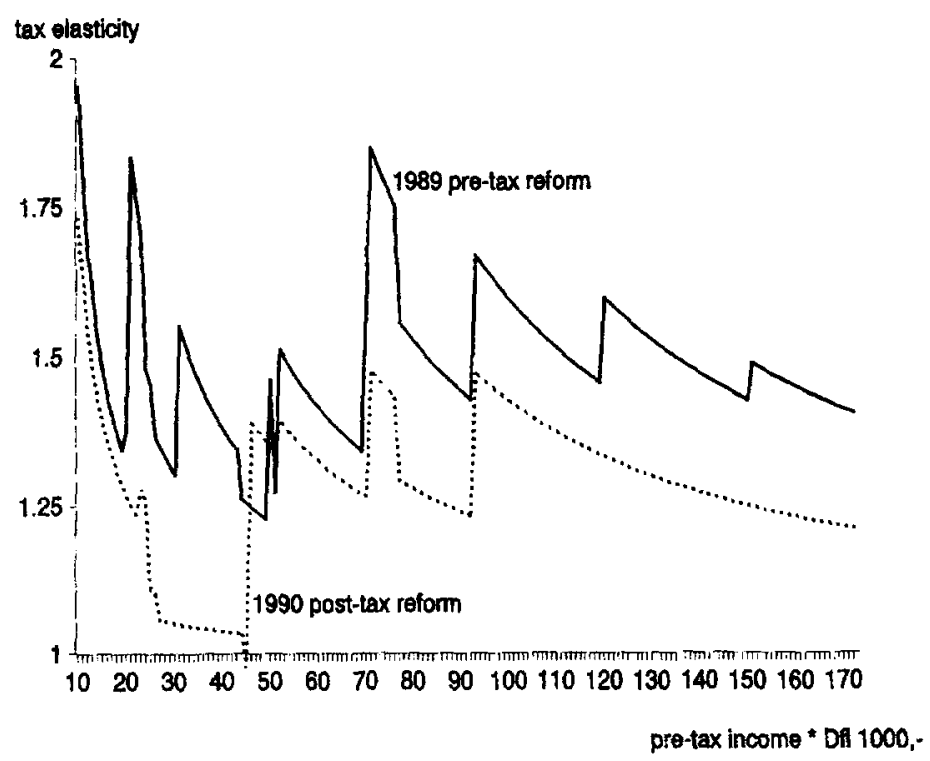

Source: Own calculations with the microtax model (Central Planning Bureau, 1990).

Figure 1. Income elasticities for individual enployees at different income levels.

attributed to the change in the rate structure. In other words, the flattening of the rate structure has a relatively minor effect (see Hutton and Lambert, 1982, p. 151). The remaining part of the total decline in the income elasticity (14.7 percent) can be attributed to the effect of other deductions and also to (minor) changes in the income distribution and in the number of taxpayers.

It should be noted that these results for the change in revenue elasticity include the threshold effect (see Section 3). A separate simulation shows that the partial threshold effect increases $\pi_{a \nu}$ by only 1.2 percentage points. It thus appears that the positive effect on the revenue elasticity of individuals changing income brackets because of the elimination of deduction, is small compared to the negative effect of the elimination itself. The results are summarized in Table 1.

One could argue that these results are biased because of our assumption that adjustment for inflation is not part of the tax system (see Section 4). However, additional simulations point out that the effects of tax reform on the income elasticity of the tax system (and thus on revenue) are still substantial in case inflation adjustment is systematically applied. With personal exemptions and income ceilings fully adjusted for inflation, both income tax revenue elasticities for 1989 and 1990 are lower (respectively, 1.30 and 1.07), but the decline resulting from the tax reform is similar.

\section{Effects on revenue}

The additional effect of the tax reform on revenue can now be determined. Starting point is tax revenue in 1989 , amounting to Dfl 66.8 billion or 13.8 percent of GDP. The relative 
Table 1. Sources of change in Dutch income tax revenue elasticity.

\begin{tabular}{lcccc}
\hline & 1989 Level & 1990 Level & Change (\%) & Share in Change \\
\hline Income tax elasticity $\pi_{a v}$ & 1.475 & 1.220 & -17.29 & 100.0 \\
$\qquad \pi_{a v}=1+:$ & & & & \\
$\begin{array}{l}\text { Effect of deductibility of social } \\
\text { security contributions }\end{array}$ & 0.039 & 0.000 & -2.64 & 15.3 \\
Effect of personal exemptions & 0.304 & 0.164 & -9.49 & 54.9 \\
Effect of rate structure & 0.161 & 0.122 & -2.62 & 15.1 \\
Residual & -0.029 & -0.066 & -2.55 & 14.7 \\
\hline
\end{tabular}

a. Including the positive threshold effect of 1.2 percentage points. This effect cannot appear as a separate entry in the table when equation (4) is used for the decomposition.

change in revenue is by definition equal to the relative change in income times the income tax elasticity. For the years after the tax reform we calculated the following weighted average income changes: 1990: +2.3 percent, 1991: +3.9 percent, 1992: +4.5 percent, 1993: +3.4 percent.$^{10}$ Using the calculated values for the income tax revenue elasticities in 1989 and 1990 , we obtain the results in Table 2 . The decline in elasticity causes a 0.6 percent lower increase in tax revenue in 1990, when compared to the revenue that would be generated by the old tax system. Note that this loss in revenue is additional to the revenue loss at the introduction of the Oort legislation. The additional revenue loss due to the tax reform rises to 3.8 percent in 1993 .

Table 2. Additional revenue loss 1990-1993.

\begin{tabular}{cccc}
\hline \multicolumn{2}{c}{$\begin{array}{c}\text { Changes in Tax Revenue with } \\
\text { Income Tax Elasticity }\end{array}$} & $\begin{array}{c}\text { Difference in } \\
\text { Percentage Points }\end{array}$ \\
\cline { 2 - 4 } & $1989^{\mathrm{a}}$ & $1990^{\mathrm{a}}$ & \\
1990 & $+3.43 \%$ & $+2.84 \%$ & -0.59 \\
1991 & $+9.31 \%$ & $+7.70 \%$ & -1.61 \\
1992 & $+16.38 \%$ & $+13.55 \%$ & -2.83 \\
1993 & $+21.89 \%$ & $+18.11 \%$ & -3.79 \\
\hline
\end{tabular}

a. Difference with respect to tax revenue in 1989.

\section{Conclusions}

It has been noted that a tax reform characterized by base broadening in exchange for a uniform proportionate rate reduction can cause a decrease in the income tax revenue elasticity (liability progression). This decrease is larger as the deductions to be eliminated are less income related. The elimination or reduction of personal exemptions, for example, causes 
a relatively sharp drop in the income tax elasticity. However, this negative effect can be (partly) compensated by either a positive effect on the tax elasticity of people changing income brackets because of the elimination of deductions (the threshold effect) or by behavioral effects. In case the revenue elasticity falls, the reformed system generates less extra revenue after income growth than the old system. The tax reform then implies a reduction in future revenue.

Our empirical analysis of the Dutch Oort reform in 1990 indeed shows such an effect. Using the microtax model of the Central Planning Bureau we calculated income tax revenue elasticities before and after the tax reform. The revenue elasticity of income taxes (including social security contributions) falls from 1.475 in 1989 to 1.220 in 1990 , a decline of 17 percent. More than 70 percent of this decline can be explained by the broadening of the tax base, while 15 percent is caused by the flattening of the rate structure. Especially the reduction of the personal exemptions has had a significant impact. The threshold effect appears to be relatively small.

Because of the lower revenue elasticity, there is a revenue loss (additional to the tax reduction at the introduction of the new legislation). Our simulations indicate a decrease in revenue by 0.6 percent in 1990 , rising to almost 3.8 percent in 1993. This substantial revenue loss was overlooked when the Oort reform was implemented. When planning a tax reform, such dynamic revenue effects should be taken into account.

\section{Acknowledgments}

We thank Victor Halberstadt, Ben van Velthoven, and Henk Vording for their useful comments on an earlier version of this paper. Michael Keen and two anonymous referees also provided many constructive and insightful suggestions. The views expressed as well as any remaining shortcomings are, of course, our own responsibility.

\section{Notes}

1. Kakwani (1977, p. 723) showed how a change in the tax schedule, holding pretax income distribution fixed, affects the redistributive effect of taxation: "If there are two tax functions yielding the same average tax rate, the tax function with the uniformly higher tax elasticity will give the post-tax income distribution more equal than the tax function with lower tax elasticity. Similarly, if the tax functions have the same tax elasticity or progressivity, the tax function with higher average tax rate gives the post income distribution more equal than the tax function with giving lower average tax rate." As Jakobsson (1976) and Khetan and Poddar (1976) have poirted out, there is a clear distinction between redistribution and tax progressivity. Some argue that the concept of residual income progression (measured by the elasticity of income after tax with respect to income before tax) is more closely connected with the redistributive effect of a tax system. For discussion see Formby, Smith, and Thistle (1990), Siber (1994), and Kiefer (1984).

2. In special cases $\alpha_{i, m}$ is a function of pretax income. When deductions are a proportion of pretax income up to a ceiling $\alpha_{i, m}$ is 1 up to the ceiling and zero beyond. If an income floor is applied, $\alpha_{i, m}$ is larger than 1 above the floor but decreasing with pretax income. In practice $\alpha_{i, m}$ can also be larger than 1 because of behavioral effects: if pretax income rises, one can be induced to make relatively more use of specific deductions.

3. A lower degree of progressivity can of course have a positive effect on pretax income growth and thus on tax revenue. However, such behavioral effects are not taken into account in this paper. 
4. See Dosser (1961), who argued that income growth can change the incidence of a tax and, as a consequence, made a distinction between static and dynamic tax incidence.

5. 1 \$US $=1.55$ Df1 (July 1995).

6. See, for example, Rijksbegroting 1992, hoofdstuk IX B, Financiën, Tweede Kamer 1991-1992, 22, 300, nr. 2, p. 149. Indeed, just as in earlier years, the inflation correction has not been fully implemented in the period 1990-1994.

7. For two reasons Kakwani's theorem $(1977$, p. 723$)$, as mentioned in note 1, cannot be applied. First, the two tax functions (1989 and 1990) do not yield the same average tax rate. Second, the tax function of 1989 has not uniformly higher tax elasticities. Thus, the distribution of tax liability in 1990 does not Lorenz dominate the distribution of tax liability in 1989.

8. The individual and group elasticities are weighted by their share in total tax revenue. In the calculations of the total weighted revenue elasticity the self-employed, elderly, and income-transfer recipients are not included because the shares of these groups in total revenue are not known in microtax 1989 and 1990 . However, this will probably not cause a substantial bias in the calculations of the change in the revenue elasticity.

9. The weighted average income tax elasticities for 1988-1993 are, respectively, 1.43, 1.48, 1.22, 1.22, 1.22, and 1.24 .

10. The ex post actual income changes of the various groups are weighted by their share in total tax revenue (source: Ministry of Social Affairs and Employment).

\section{References}

Central Planning Bureau. (1988). Eenvoud verzekerd: Microkax 88. Working Paper No. 43. 's-Gravenhage.

Central Planning Bureau. (1990). Het koopkrachtoverzicht; Onderbouwing koopkracht en Microtax 1990. Working Paper No. 35. 's-Gravenhage.

Cnossen, S., and K. Messere. (1990). "Income Tax Reforms in OECD Member Countries." Bulletin International Bureau of Fiscal Documentation, 463-483.

De Kam, C.A. (1993). "Tax Policies in the 1980s and the 1990s: The Case of the Netherlands." In A. Knoester (ed.), Taxation in the United States and Eunope (pp. 355-377). London.

Dosser, D. (1961). "Tax Incidence and Growth." Economic Joumal 71, 572-579.

Formby, J.P., W.J. Smith, and P.D. Thistle. (1990). "The Average Tax Burden and the Welfare Implications of Global Tax Progressivity." Public Finance Quarterly 18(1), 3-24.

Fries, A., J. Hutton, and P. J. Lambert. (1982). "The Elasticity of the U.S. Individual Income Tax: Its Calculations, Determinarts and Behavior." Review of Economics and Statistics 64, 147-151.

Hutton, J.P., and P.J. Lambert. (1980). "Evaluating Income Tax Revenue Elasticities." Economic Joumal 90, 901-906.

Hutton, J.P., and P.J. Lambert. (1982). "Modelling the Effects of Income Growth and Discretionary Change in the Sensitivity of UK Income Tax Revenue." Economic Journal 92, 145-155.

Jakobsson, U. (1976). "On the Measurement of the Degree of Progression." Joumal of Public Economics 5, 161-168.

Kakwani, N.C. (1977). "Applications of Lorenz Curves in Economic Analysis." Econometrica 45(3), 719-727.

Khetan, C.P., and S.N. Poddar. (1976). "Measurement of Income Tax Progression in a Growing Economy: The Canadian Experience." Canadian Journal of Economics 9(4), 613-629.

Kiefer, D.W. (1984). "Distributional Tax Progressivity Indexes." National Tax Joumal 37(4), 497-513.

Lambert, P.J., and W. Pfahler. (1992). "Income Tax Progression and Redistributive Effect: The Influence of Changes in the Pre-Tax Income Distribution." Public Finance 47(1), 1-16.

Musgrave, R.A., and T. Thin. (1948). "Income Tax Progression, 1929-48." Journal of Political Economy 56, 498-514.

Norregaard, J. (1990). "Progressivity of Income Tax Systems." OECD Economic Studies 15, 83-110.

OECD. (1984). "Tax Elasticities of Central Government Personal Income Tax Systems." OECD Studies in Taxation 1-49.

Ram, R. (1991). "Elasticity of Individual Income Tax in the United States: Further Evidence from Cross-Section Data." National Tax Journal 44, 93-99. 
Silber, J. (1994). "Income Distribution, Tax Structure, and the Measurement of Tax Progressivity." Public Finance Quarterly 22(1), 86-102.

Tanzi, V. (1969). "Measuring the Sensitivity of the Federal Income Tax from Cross-Section Data: A New Approach." Review of Economics and Seatistics 51, 206-209.

Tanzi, V. (1976). "The Sensitivity of the Yield of the U.S. Individual Income Tax and the Tax Reforms of the Past Decade." International Monetary Fund Staff Ptpers 23, 441-454.

Tweede Kamer. (1992). Rijksbegroting 1992, hoofdstuk IX B, Financiën, Tweede Kamer 1991-1992, nr. 2, 149. Wellink, A.H.E.M. (1974). "Sensitivity of Personal Income Tax Revenue." National Tax Joumal 27, 357-360. Wellink, A.H.E.M. (1975). De inkomenselasticiteit van het Nederlandse belastingstelsel. Leiden. 